\title{
ПЕРВОЕ ПОРАЖЕНИЕ БОРИСА ДЖОНСОНА
}

Аннотация. 1 августа 2019 г. состоялись дополнительные выборы в британский парламент по избирательному округу в Уэльсе. Кандидат от Консервативной партии потерпел поражение - победу на них одержала Партия либеральньх демократов. $У$ Лейбористской партии четвёртый результат. Парламентское большинство правительства Б. Джонсона при поддержке партии ольстерских юнионистов сократилось до 1 голоса. Последствия для правительства носят судьбоносный характер. Вероятность досрочных выборов повышает-ся.

Ключевые слова: брекзит, Борис Джонсон, британский парламент, Европейский союз, Лейбористская партия, Консервативная партия, партия «Брекзит», Партия либеральных демократов.

3 сентября 2019 г. депутаты британского парламента возвращаются в Вестминстер после летних каникул. Расстановка сил в парламенте стала для консерваторов хуже: 1 августа состоялись дополнительные выборы в избирательном округе Брекон-энд-Рэдношир (Уэльс), на которых кандидат от тори потерпел поражение. Соответственно, шаткое правительственное большинство сократилось до 1 голоса.

\section{Отзыв депутата}

Дополнительные выборы были назначены ввиду того, что 19\% избирателей подписали петицию об отзыве депутата-консерватора Криса Дэвиса, обвинённого в нецелевом расходовании казённых средств, ассигнованных на его депутатскую деятельность ${ }^{1}$. Свою вину К. Дэ-вис признал, но Консервативная партия вновь выдвинула его в качестве кандидата на этих до-полнительных выборах.

Следует отметить, что в демократической Британии процедура отзыва депутата была введена лишь в 2015 г. Избиратели вправе отозвать депутата, если суд признает его виновным в нарушении закона и приговорит к тюремному заключению сроком менее одного года (при поражении по всем апелляциям); если парламентария отстраняют от исполнения депутатских обязанностей более чем на десять дней (по докладу Комиссии по этике - Committee on Standards); если ему выносят приговор за нецелевое использование средств на депутатскую деятельность.

В первом случае депутата автоматически лишают мандата, и петиция избирателей не требуется. В остальных случаях открывается петиция, которую в течение шести недель дол-

(C) Ананьева Елена Владимировна - кандидат философских наук, ведущий научный сотрудник, руководитель Центра британских исследований Отдела страновых исследований Института Европы РАН. Adpec: 125009, Россия, Москва, ул. Моховая, д. 11, стр. 3. E-mail: e-ananieva@yandex.ru.

DOI: http://dx.doi.org/10.15211/vestnikieran420198186

1 Tory MP Chris Davies guilty of false expenses claim. 22.03.2019. URL: https://www.bbc.com/news/uk-wales47667080/ (дата обращения: 23.03.2019). Дэвис обязан выплатить штраф, возместить судебные издержки и был приговорён к 50 часам общественных работ. 
жны подписать $10 \%$ зарегистрированных избирателей, чтобы были объявлены дополнительные выборы. Действующий депутат имеет право вновь выставить свою кандидатуру.

В Британии процедура отзыва депутата применяется лишь во второй раз. Впервые дополнительные выборы в связи с отзывом депутата прошли 6 июня 2019 г. в округе Петерборо: депутат от Лейбористской партии (ЛПВ) Фиона Онасанья была осуждена за ложь по поводу превышения скорости (петицию за отзыв подписали около 30\% избирателей). Дополнительные выборы выиграла Лейбористская партия (31\%), утратив 27\% голосов и вырвав победу у партии «Брекзит» Н. Фараджа (29\%), а консерваторы заняли третье место $(21 \%)$, потеряв $25 \%$ голосов избирателей ${ }^{1}$. Примечательно, что кандидат лейбористов одержал победу в округе, в котором подавляющее большинство граждан высказалось за брекзит на референдуме 2016 г.

В 2018 г. депутат от Демократической юнионистской партии (ДЮП) Йан Пейсли (сын известного правого политического деятеля Й. Пейсли) был отстранён от исполнения депутатских обязанностей на тридцать дней. Однако петиция не набрала достаточного количества подписей, и Й. Пейсли сохранил мандат.

В округе Брекон-энд-Рэдношир избиратели проявили активность, обеспечив самую высокую явку на дополнительные выборы с 1997 г. Мандат получил кандидат Партии либеральных демократов (ПЛД). Консерваторы оказались на втором месте, несмотря на то, что в округ нанесли визиты сам премьер, новый лидер Палаты общин Дж. Рис-Могг (ведущий брекзитёр во фрак-ции тори) и М. Гоув (брекзитёр, ныне министр без портфеля, ответственный за подготовку к брекзиту без сделки). Партия «Брекзит» оказалась на третьем месте $^{2}$, а ЛПВ - на четвёртом, что стало для неё серьёзным ударом.

В отличие от дополнительных выборов в июне в округе Петерборо, более мелкие партии (Плайд Камри и «Зеленые»), выступающие за членство Британии в Европейском союзе (бремейнеры), не стали выставлять собственных кандидатов, заключив пакт с ПЛД, чтобы по-высить шансы на победу своих политических союзников, что им удалось (ПЛД последовательно проевропейская партия). Партии брекзитёров не объединили усилия: партия «Брекзит» отобрала голоса у тори. Не объединили усилия и крупные партии бремейнеров: либерал-де-мократы отобрали голоса у лейбористов. Однако в целом партии брекзитёров и бремейнеров набрали примерно равные доли голосов ${ }^{3}$.

\section{Расстановка сил в парламенте}

Как правило, смена главы правительства в первое время обеспечивает преемнику приток симпатий избирателей $(42 \%$, Корбин - 21\%, при очень высокой доле неопределившихся $34 \%)^{4}$. Всплеск доверия к новому премьер-министру может снизиться, как произошло раньше с Г. Брауном и Т. Мэй, которые пользовались симпатиями британцев по вступлении в дол-жность. Они стали премьер-министрами фактически по «коронации» (их соперники

\footnotetext{
${ }^{1}$ Peterborough by-election: Labour beats Brexit Party to hold seat. 07.06.2019. URL: https://www.bbc.com/news/ukpolitics-48532869 (дата обращения: 05.08.2019).

${ }^{2}$ Н. Фарадж, брекзитёр, основал партию в январе 2019 г. ввиду фактического распада Партии независимости Соединённого Королевства, которую ранее возглавлял. Проиграв дополнительные выборы в июне и в августе, партия «Брекзит» не смогла провести своих депутатов в общенациональный парламент, хотя обладает высоким рейтингом по опросам общественного мнения.

${ }^{3}$ Brecon and Radnorshire by-election: Lib Dems beat Conservatives. 02.08.2019. URL: https://www.bbc.com/news/ukwales-politics-49200636 (дата обращения: 05.08.2019).

${ }^{4}$ Voting Intention: Con 32\%, Lab 22\%, Lib Dem 19\%, Brex 13\% (29-30 July). URL: https://d25d2506sfb94s. cloud front.net/cumulus_uploads/document/twa1h7mn6m/TimesResults_190730_VI_Trackers_w.pdf (дата обращения: 05.08.2019)
} 
сняли свои кандидатуры, и им не пришлось проходить даже этап голосования членов своей партии). Гордон Браун, сменив Т. Блэра в 2007 г., так и не решился провести досрочные выборы, чтобы получить мандат избирателей страны (а очередные выборы 2010 г. ЛПВ проиграла). Т. Мэй, став лидером партии тори в 2016 г., потерпела по существу поражение на досрочных вы-борах 2017 г. (фракция Консервативной партии осталась самой крупной в парламенте, но, ут-ратив большинство, правит благодаря поддержке десяти депутатов ДЮП).

После победы Б. Джонсона на выборах лидера партии и его назначения премьер-министром опросы показывают (без учёта неопределившихся), что Консервативная партия получила преимущество над ЛПВ в 3-10 п.П., повысив свой рейтинг за счёт партии «Брекзит», но не слишком значительно. Вместе с тем, политические предпочтения бремейнеров распределены между ЛПВ и ПЛД ${ }^{1}$. Однако результаты опросов представляют собой усредненные пропорциональные данные по всей стране, а парламентские выборы проходят по мажоритарной системе относительного большинства, искажающей предпочтения избирателей.

Между тем, реальное положение дел - расстановка политических сил в Вестминстере («парламентская арифметика») стала для консерваторов хуже после дополнительных выборов в округе Брекон-энд-Рэдношир. Консервативная партия набрала 311 мест (снижение на 7 мандатов с 318 - по итогам выборов 2017 г.), её союзник ДЮП - 10 мест; Оппозиция Её Величества - 319 мест: ЛПВ - 247, Шотландская национальная партия (ШНП) - 35, независимые - 16, ПЛД - 13, «Независимая группа за изменения» - $5^{2}$, Плайд Камри (Уэльс) -4 , «Зелёные» -1 .

Количество депутатских мест в парламенте - 650. Из них 7 мандатов принадлежат партии Шинн Фейн, которая участвует в выборах, но не принимает участие в работе парламента, поскольку не желает приносить присягу Королеве. Спикер Палаты общин (ныне консерватор Дж. Беркоу) принимает статус беспартийного на время исполнения обязанностей и по должности имеет право участвовать в голосовании лишь в одном случае при равенстве голосов по законопроекту ${ }^{3}$. Заместители спикера (первый заместитель - от оппозиции, два заместите-ля - по одному от партии спикера и от оппозиции) не принимают участие в голосовании - их трое. Таким образом, рабочее большинство в парламенте составляет 320 голосов (650 минус 11$)$.

Столь скрупулезный подсчёт необходим, поскольку ввиду итогов дополнительных выборов парламентское большинство, которым может располагать премьер-министр Б. Джонсон, снизилось до одного голоса ${ }^{4}$, а политические ставки повысились.

Утрата консерваторами мандата на последних дополнительных выборах стала первым поражением нового главы правительства меньшинства (самое скорое за послевоенный период). Расстановка сил такова, что провести законопроекты через парламент Б. Джонсон сможет только в том случае, если получит поддержку всех членов фракции консерваторов и ДЮП. Большинство депутатов нынешнего состава парламента выступают против позиции премьер-министра вывести Британию из Евросоюза 31 октября «во что бы то ни стало» (do or die, co-me what may) - даже без сделки. Разногласия среди депутатов-тори столь остры,

\footnotetext{
${ }^{1}$ UK Polling Report. 01.08.2019. URL: https://ukpollingreport.co.uk/ (дата обращения: 05.08.2019).

2 Образована в феврале 2019 г. из депутатов, вышедших из Консервативной и Лейбористской партий. Первоначально составляла 11 депутатов. Получила регистрацию в качестве партии «Изменим Британию». После провала на выборах в Европейский парламент в мае 2019 г. из её состава вышли 6 человек.

3 Как правило, спикер голосует за сохранение статус-кво.

${ }^{4}$ Current State of the Parties. URL: https://www.parliament.uk/mps-lords-and-offices/mps/current-state-of-the-parties/ (дата обращения: 05.08.2019).
} 
что некоторые члены его фракции готовы голосовать за недоверие собственному правительству, пре-дотвращая подобный исход брекзита. Однако их будет сдерживать вероятность того, что зна-чительная часть депутатских мандатов в Англии перейдёт к либерал-демократам. Должность премьер-министра может перейти к лидеру лейбористов Дж. Корбину, которого они считают слишком левым.

Более того, брекзит без сделки грозит распадом Соединённого Королевства - недаром первые свои визиты Б. Джонсон нанёс в Шотландию и Северную Ирландию.

\section{Политические настроения в регионах}

Шотландские тори не желают досрочных выборов, поскольку опасаются потерять мандаты (в 2017 г. их количество резко возросло: с 1 до 13 мандатов). Тогда часть избирателей-юнионистов, отнюдь не сторонников Консервативной партии, проголосовала тактически - против националистов из ШНП. В случае досрочных общенациональных выборов, которые неизбежно станут референдумом по брекзиту, их голоса могут отойти лейбористам и ШНП, поскольку на референдуме 2016 г. Шотландия большинством в 62\% выступила за членство в Европейском союзе. Всё же ни Дж. Корбин, ни Б. Джонсон не пользуются симпатиями в регионе, и политический кризис в Лондоне способствует тому, что идея независимости Шотландии не сходит с повестки дня. ШНП в пользу независимости выдвигает аргумент о всё бо-лее глубоком различии Шотландии и Англии (как региона), несовместимости их политических культур, о чём свидетельствует приход к власти Б. Джонсона. Лидеру шотландских кон-серваторов Рут Дэвидсон следует завоевать поддержку юнионистов (даже при неприятии ими личности и политики премьер-министра), чтобы они голосовали в противовес ШНП на выбо-рах в парламент Шотландии 2021 г. Эти выборы станут, по сути, референдумом о независимости региона, считает обозреватель А. Мэсси ${ }^{1}$.

В Северной Ирландии Арлин Фостер, лидер ДЮП, в унисон с Б. Джонсоном обвинила переговорщиков Брюсселя в «воинственности», загнавших переговоры в тупик с истинной целью «вызвать распад Соединённого Королевства», а не заключить соглашение ${ }^{2}$, поскольку «бэкстоп» (режим ирландской границы, оговорённый в соглашении) отделил бы Северную Ирландию от остальной территории страны. Сам премьер-министр выдвинул ультиматум не встречаться с руководителями ЕС, пока они не откажутся от «бэкстопа». Однако Евросоюз и Республика Ирландия стоят на своей прежней позиции: пересмотра Соглашения о выходе Британии из ЕС не будет.

Правительство меньшинства Б. Джонсона критически зависит от поддержки ДЮП в парламенте. По этой причине премьер-министр заверил А. Фостер, что он «не будет нейтральным» в отношении территориальной целостности королевства, но сохранит беспристрастность в вопросе формирования правительства Северной Ирландии ${ }^{3}$, останется привержен Белфастскому соглашению $1998 \Gamma_{.}^{4}{ }^{4}$ и не поддерживает идею референдума о воссоединении Северной Ирландии с Республикой Ирландия. Лидер Шинн Фейн, Мэри Лу Макдоналд, выразила серьёзные сомнения в беспристрастности Джонсона и выступила с требованием

\footnotetext{
${ }^{1}$ Massie A. Johnson's premiership confirms the trend: Scotland and England have never felt so far apart. August 1, 2019. URL: https://www.prospectmagazine.co.uk/politics/johnsons-premiership-confirms-the-trend-scotland-andengland-have-never-felt-so-far-apart-independence-snp (дата обращения: 05.08.2019).

${ }^{2}$ Brexit bombshell: DUP's Foster reveals Brussels' true goal in talks - and it's not a deal. The Express. 01.08.2019.

3 В Северной Ирландии ДЮП и Шинн Фейн не могут договориться о формировании правительства более 2,5 лет.

${ }^{4}$ Согласно соглашению, граница между северной Ирландией и Республикой Ирландия должна быть открыта, что противоречит намерению Джонсона провести брекзит без сделки, несмотря на его заявления, что на границе не будет создана пограничная инфраструктура ни при каких обстоятельствах.
}

Научно-аналитический вестник ИЕ РАН, 2019, №4 
провести референдум «о границе» в случае брекзита без сделки.

В этой связи позиции Джонсона осложняются и в США. Торговое соглашение между Вашингтоном и Лондоном, которое обещал Д. Трамп, может не получить одобрение в Конгрессе, где велико влияние лобби американцев ирландского происхождения, объединённых в группу «Друзья Ирландии» ${ }^{1}$.

\section{Фрагментация политического поля}

Н. Фарадж заявил, что весьма вероятно, что в Британии будет проведены две избирательные кампании в течение следующего полугода ${ }^{2}$. Действительно, активно идут спекуляции о досрочных выборах. Единственная возможность провести выборы до 31 октября - намечен-ной даты выхода Британии из ЕС - объявить вотум недоверия правительству, и инициатива должна исходить от Дж. Корбина как лидера оппозиции. Если вотум недоверия будет внесен 3 сентября, то, согласно процедуре, выборы пройдут 24 октября - за неделю до брекзита. Сам Джонсон намерен объявить досрочные выборы после выхода Британии из Евросоюза (весной), учитывая и фактор непопулярности Корбина.

Межпартийное соперничество носит настолько острый характер, что идейно близкие партии заявляют, что не будут заключать предвыборные пакты. Выступающие за выход Британии из ЕС Консервативная партия и партия «Брекзит» исключают сотрудничество: Джонсон отверг соответствующее предложение Фараджа (пусть и получившее одобрение Трампа), рассчитывая вернуть избирателей в лоно своей партии, а Фарадж стал обвинять премьер-ми-нистра в демагогии (брекзит без сделки - его переговорная уловка, которая к реальности не имеет отношения).

Точно также новый лидер либерал-демократов Джо Суинсон заявила, что ПЛД не станет вступать в предвыборный союз с Лейбористской партией, пока во главе неё стоит Дж. Корбин ${ }^{3}$. Корбин не пользуется особой популярностью, и рейтинг тори пока выше рейтинга лейбористов на 10 п.п. ${ }^{4}$

Корбин неоднократно заявлял, что внесёт вотум недоверия, когда будет уверен в победе лейбористов на выборах. Таким образом, даже если правительство Джонсона падет, успех лейбористов на выборах не обеспечен, а коалиции на данном этапе исключены. При нынешних рейтингах партий, к которым всё же следует относиться с осторожностью, вероятны фор-мирование «подвешенного парламента» при распаде двухпартийной системы (бинарной оппозиции консерваторов и лейбористов) и новая патовая ситуация в Вестминстере. Отсюда и прогноз Н. Фараджа о повторных выборах. Правда, если Джонсон выведет Британию из ЕС 31 октября, и выборы состоятся по его сценарию, то шансы партии самого Фараджа сойдут на нет.

\section{Выводы}

\footnotetext{
${ }^{1}$ В США насчитывается 33 млн американцев ирландского происхождения. The Express. 31.07.2019.

2 «We WON'T leave EU!» Nigel Farage declares war on Johnson with shock Brexit admission. 03.08.2019. URL: https://www.express.co.uk/news/politics/1161288/brexit-news-nigel-farage-brexit-party-boris-johnson-october-31-nodeal-brexit (дата обращения: 05.08.2019).

${ }^{3}$ Напомним, что ПЛД не стала заключать пакт с ЛПВ (своим естественным союзником) накануне выборов 2010 г., ставя такое же условие - смена непопулярного лидера (Г. Брауна). Заключив коалиционное соглашение и войдя в правительство тори, либерал-демократы утратили доверие избирателей, потерпев сокрушительное поражение на выборах 2015 г. за соглашательство. Восстановили политическую репутацию лишь на выборах в Европейский парламент (май 2019 г.).

4 Voting Intention: Con 32\%, Lab 22\%, Lib Dem 19\%, Brex 13\% (29-30 July). URL: https://d25d2506sfb94s.cloud front.net/cumulus_uploads/document/twa1h7mn6m/TimesResults_190730_VI_Trackers_w.pdf (дата обращения: 05.08.2019).
} 
Политическая ситуация в Британии обостряется по мере приближения даты выхода Британии из Европейского союза. Парламентское большинство правительства меньшинства Б. Джонсона при поддержке ДЮП сократилось до одного голоса. Оно может утратить его ввиду выхода из партии или «бунта» заднескамеечников-тори, не согласных с намерением (истинным или демагогическим) премьер-министра вывести страну из ЕС без сделки, если Брюс-сель не пойдёт на уступки по «бэкстопу». Вероятность досрочных выборов повышается, одна-ко вряд ли разрешит патовую ситуацию в парламенте при фрагментации политических сил, преследующих узкопартийные интересы и не желающих заключать союзы.

\section{References}

Agreement on the withdrawal of the United Kingdom of Great Britain and Northern Ireland from the European Union and the European Atomic Energy Community, as endorsed by leaders at a special meeting of the European Council on 25 November 2018. Withdrawal Agreement and Political Declaration; political declaration setting out the framework for the future relationship between the European Union and the United Kingdom.

Massie A. Johnson's premiership confirms the trend: Scotland and England have never felt so far apart. Prospect magazine. August 1, 2019.

Voting Intention: Con 32\%, Lab 22\%, Lib Dem 19\%, Brex 13\% (29-30 July). Yougov.co.uk. URL: https://d25d2506sfb94s.cloudfront.net/cumulus_uploads/document/twa1h7mn6m/TimesRe sults_190730_VI_Trackers_w.pdf.

\section{The First Defeat of PM Boris Johnson}

Author. Elena Ananieva, Candidate of Sciences (Philosophy), Head of the Centre for UK Studies, Department of Countries Studies, Institute of Europe, Russian Academy of Sciences. Address: 11-3, Mokhovaya str., Moscow, Russia, 125009. E-mail: e-ananieva@yandex.ru.

Abstract. The returns of the by-election in Wales to the UK parliament boosting the Libdems dealt a huge blow to the new PM: Boris Johnson is left just a one-seat working majority with the support of DUP. The Labour party came fourth after the «Brexit» party. The parliamentary arithmetics are fateful for the UK minority government. Early elections seem imminent.

Key words: Brexit, Boris Johnson, UK parliament, European Union, Labour Party, Conservative Party, political crisis, Libdems, N. Farage.

DOI: http://dx.doi.org/10.15211/vestnikieran420198186 